\title{
Berbamine application beyond cancer
}

\author{
Navneet O. Soni* \\ Department of Pharmacology, NPDCH, Visnagar, Gujarat, India \\ Received: 25 July 2021 \\ Accepted: 27 August 2021 \\ *Correspondence: \\ Dr. Navneet O. Soni, \\ Email: navneetsoni1978@yahoo.com \\ Copyright: (C) the author(s), publisher and licensee Medip Academy. This is an open-access article distributed under \\ the terms of the Creative Commons Attribution Non-Commercial License, which permits unrestricted non-commercial \\ use, distribution, and reproduction in any medium, provided the original work is properly cited.
}

\begin{abstract}
The main purpose of this review was to ascertain the clinical application and future non oncological uses of Berbamine. Berbamine, as a STAT3 (signal transducer and activator of transcription) inhibitor, antioxidant, anti-inflammatory and modulator of many signalling pathways, should be investigated in autoimmune diseases. Berbamine has been found to have pharmacological activity in the following cancers: breast cancer, lung cancer, prostate cancer, pancreatic cancer, ovarian cancer, glioblastoma, colon cancer, bladder cancer, chronic myeloid leukemia, hepatocellular carcinoma, triple negative breast cancer and osteosarcoma. Ischemic reperfusion injury, melanoma, COVID-19 and allergy diseases are among the conditions for which it is beneficial. It may aid in the treatment of obesity, metabolic syndrome, inflammatory syndrome, sepsis, COVID-19, dengue fever, Nipah virus infection, influenza, solid tumors, lymphoma, cancer, hematological malignancies, skin inflammatory disorder and atopic dermatitis. Berbamine can be used as versatile molecule in alcoholic liver disease, diabetic nephropathy and antiviral, anti-inflammatory.
\end{abstract}

Keywords: Cancer, Diabetic nephropathy, Anti-inflammatory, Reperfusion injury, COVID-19

\section{INTRODUCTION}

Berbamine is a natural chemical derived from the Chinese herb Berberis amurensis. ${ }^{1}$ Berbamine, a bisbenzylisoquinoline alkaloid, has been utilized for many years in China to treat clinical patients with inflammation and cancer. ${ }^{2}$

\section{Mechanism of action $^{3-42}$}

The mechanism of action is as follows. ${ }^{3-42}$ It activates and inhibits a large number of pathway and transcription factors. Berbamine activates intrinsic apoptotic process, it is STAT3 antagonist. Inhibition of the $\mathrm{Wnt} / \beta$-catenin signaling pathway by berbamine in the intracellular environment. Modulate reactive oxygen species via NF- $\kappa \mathrm{B}$ is done. Berbamine compounds synthesized synthetically inhibit JAK2/STAT3 signaling. Berbamine activates the apoptotic signaling pathway, which is regulated by the p53 gene. Berbamine induces apoptosis (cell death) in cancer via the Fas protein. The c-Maf, PI3K/Akt and MDM2-P53 pathways are all involved. It works by inhibiting the NF$\kappa \mathrm{B}$ and MAPK signaling pathways, both of which are involved in inflammation. Caspase activation occurs with berbamine. Berbamine acts on $\mathrm{Na}^{+} / \mathrm{K}^{+}$ATPase. Berbamine protects against SARS-CoV-2 infection by inhibiting ACE2 endolysosomal trafficking mediated by TRPMLs. Prostaglandins and leukotrienes production are inhibited. By maintaining cytosolic $\mathrm{Ca}^{2+}$ homeostasis and blocking calpain activation, it protects against ischemia/reperfusion. The mTOR/SREBP-1c axis is regulated by Berbamine induced AMPK activation. It regulates the expression of eNOS and iNOS. Berbamine regulates autophagy in cells.

\section{Berbamine its uses}

Breast cancer, lung cancer, prostate cancer, pancreatic cancer, ovarian cancer, glioblastoma, colon cancer, bladder cancer, chronic myeloid leukemia, hepatocellular carcinoma, triple negative breast cancer, osteosarcoma, ischemic reperfusion injury, melanoma, COVID-19, antioxidant. ${ }^{3-42}$ 


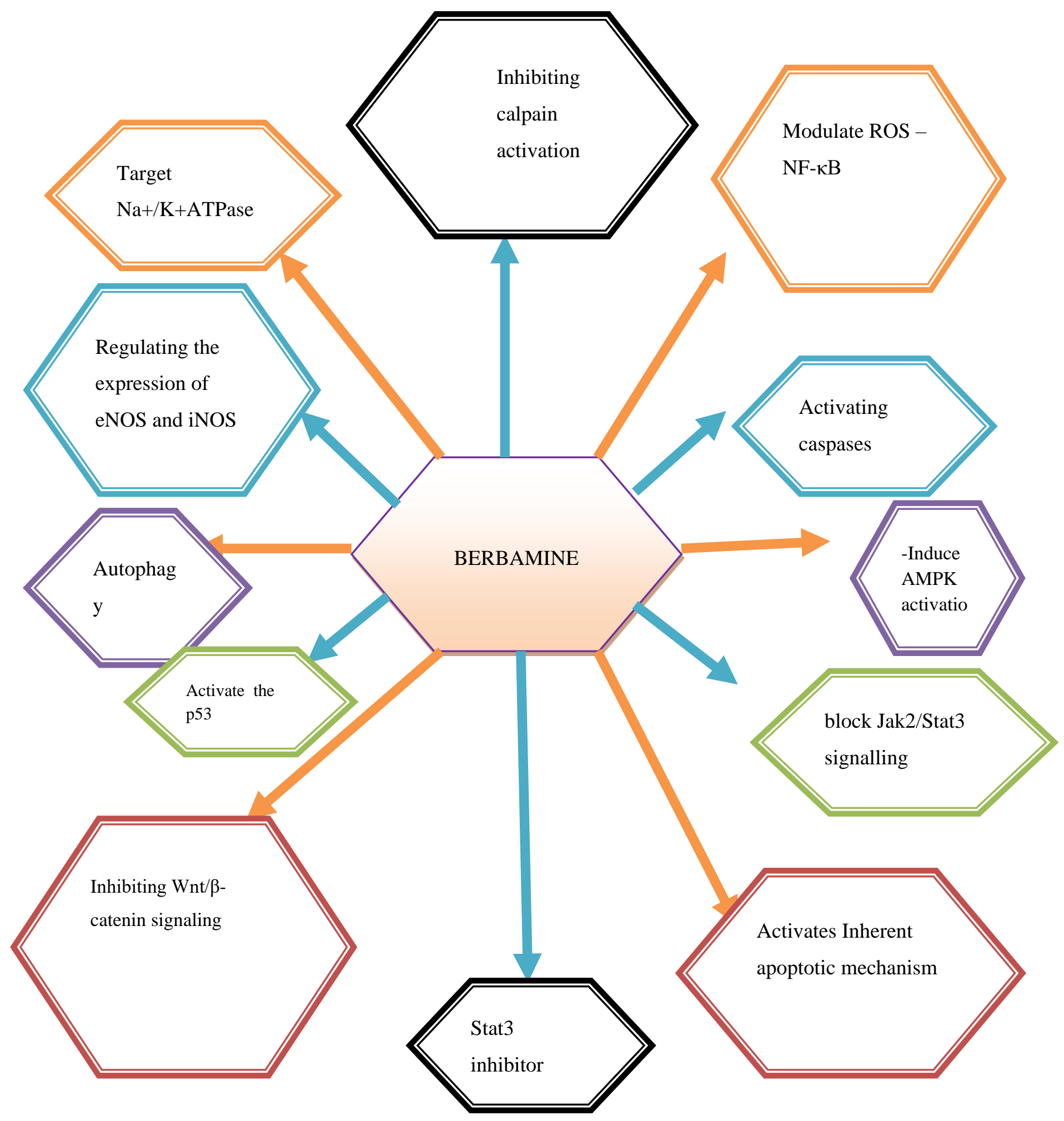

Figure 1: Mechanism of action.

\section{Berbamine in cancer}

Berbamine curbs the growth of liver cancer cells as well as cancer-initiating cells. ${ }^{3}$ BER inhibits the proliferation, migration and invasion of highly metastatic human breast cancer cells. ${ }^{4}$ Berbamine was tested for anticancer activity in vitro experiments and in vivo experiments in the treatment of lung cancer. ${ }^{5}$ Berbamine reduced the 
development of prostate cancer cells in vivo experiments and in vitro by experiments activating an inherent apoptotic mechanism. ${ }^{6}$

Berbamine improves gefitinib effectiveness by decreasing STAT3 activation in pancreatic cancer cells. ${ }^{7}$ Berbamine inhibits cell proliferation and provokes apoptosis (cell death) in ovarian cancer via inhibiting $\mathrm{Wnt} / \beta$-catenin signaling. ${ }^{8}$ A new Berbamine derivative decreases cell viability and promotes apoptosis in human glioblastoma cancer stem-like cells. ${ }^{9}$ Berbamine has anticancer properties in human colon cancer cells by inducing autophagy and apoptosis and inhibiting cell migration. ${ }^{10}$ Berbamine suppresses bladder cancer progression by modulating the ROS/NF-B axis. ${ }^{11}$ Novel synthetic Berbamine derivatives block JAK2/STAT3 signaling and induce apoptosis in human melanoma cells. ${ }^{12}$

Berbamine's emerging role as an anti-cancer medication in systemic malignancies other than chronic myeloid leukemia is being studied further. ${ }^{13}$ To treat stomach cancer, polymeric carriers are used to transport the chemotherapy drugs paclitaxel and Berbamine. ${ }^{14}$ Berbamine hinders cell viability and causes cell death (apoptosis) in colorectal cancer cells through activating the p53-dependent apoptotic signaling pathway. ${ }^{15}$ Berbamine suppresses tumor growth in nude mice by inducing Fasmediated apoptosis (cell death) in carcinoma of liver (HepG2 cells lines). ${ }^{16}$ Berbamine has a superior radiosensitizing effect in vitro and in vivo for head and neck squamous cell cancer. ${ }^{17}$

Berbamine inhibits cell proliferation and migration while also inducing cell death in lung cancer cells via the c-Maf, PI3K/Akt and MDM2-P53 pathways. ${ }^{18}$ Amalgamation of detoxified pneumolysin derivative (A146Ply) and Berbamine as a breast cancer treatment. ${ }^{19}$ Berbamine reduces inflammation by inhibiting the NF- $\mathrm{B}$ and MAPK signaling pathways. ${ }^{20}$ Berbamine causes apoptosis in the human hepatoma cell line SMMC7721 via reducing mitochondrial transmembrane potential and activating caspases. ${ }^{21}$ Berbamine has significant anticancer effects in vitro and in vivo on imatinib-resistant CML cells. ${ }^{22}$

Berbamine and ouabain, which target $\mathrm{Na}^{+} / \mathrm{K}^{+}$ATPase, work along with sorafenib to inhibit hepatocellular cancer. ${ }^{23}$ Natural substance Berbamine improves doxorubicin treatment efficacy in triple negative breast cancer. ${ }^{24}$ Berbamine has anti-proliferative effect on k562 resistant cells via inhibiting the NF- $\kappa \mathrm{B}$ pathway. ${ }^{25}$ Berbamine induces (cell death) apoptosis in human leukemia Jurkat cells in an experimental investigation. ${ }^{26}$ Berbamine prevents neutropenia caused by imatinib and allows for cytogenetic reactions in Chinese patients with long duration of chronic myeloid leukaemia. ${ }^{27}$

Berbamine, a natural STAT3 inhibitor, enhances the antigrowth and pro apoptotic effects of sorafenib on hepatocellular carcinoma cells synergistically. ${ }^{28}$ Berbamine is a new bcr/abl fusion gene inhibitor with significant anti-leukemia action. ${ }^{29}$ Through the stimulation of ROS/JNK signaling, a Berbamine derivative promotes apoptosis in chemotherapy-resistant human osteosarcoma cells. $^{29}$ Berbamine, a new nuclear factor $\mathrm{B}$ inhibitor, suppresses proliferation and promotes death in human myeloma cells. ${ }^{30}$ Berbamine shields the heart from the damage caused by ischemia/reperfusion by preserving cytosolic $\mathrm{Ca}^{2+}$ homeostasis and inhibiting calpain activation. ${ }^{31}$ Berbamine and paclitaxel have synergisti anticancer actions in glioma cells via the ROS/Akt pathway. ${ }^{32}$

Berbamine reduces ethanol-induced liver damage in mice via inhibiting hepatic inflammation. ${ }^{33}$ Human melanoma cells are killed by novel synthetic Berbamine derivatives that inhibit JAK2/STAT3 signaling. ${ }^{34}$ Berbamine is a potent inhibitor of human in fibroblast. ${ }^{35}$ Berbamine, a natural occurring compound which is CaMKII inhibitor, has anti-angiogenic and anticancer properties against glioblastoma. ${ }^{36}$ Berbamine prevents SARS-CoV-2 infection by interfering with TRPMLs-mediated ACE2 endolysosomal trafficking. ${ }^{37}$ The plant alkaloids tetrandrine and Berbamine inhibit the production of prostaglandins and leukotrienes. ${ }^{38}$ Berbamine stimulate AMPK activation normalize the mTOR/SREBP-1c axis and the Nrf2/ARE pathway in steatotic (lipid accumulation) HepG2 cell units, alleviating lipid accretion and oxidative stress. ${ }^{39}$ Berbamine analogues protect against aminoglycoside-induced hair cell death in distinct ways. ${ }^{40}$ Berbamine shields the heart from isoproterenol-induced myocardial infarction in rats via regulating the expression of eNOS and iNOS.41 Through autophagy regulation, Berbamine post conditioning shields the myocardium from ischemia/reperfusion injury. ${ }^{42}$

\section{Non-oncological uses of Berbamine}

\section{Diabetic nephropathy}

A new potential target in diabetic nephropathy has been identified. $^{43-57}$ The Wnt/ $\beta$-catenin signaling pathway is involved in mesangial cell extracellular matrix (ECM) production (MCs). ${ }^{58}$ Through the JNK/NF-B/NADPH oxidase/ROS pathway, high glucose promotes renal mesangial cell proliferation and fibronectin expression. ${ }^{59}$ High glucose (HG) activated NF-B signaling and increased TLR4 and MCP-1 expression. ${ }^{60}$ NF-B-mediated increased inflammation, possibly via ROS. STAT3 inhibition in tubular epithelial cells protects against kidney fibrosis and nephropathy. ${ }^{61}$ Discriminating activation of AMPK including its isoforms recovers renal function in a diabetic nephropathy rat model. ${ }^{62}$ Bunge et al notoginseng is a Chinese formula for diabetic nephropathy (in vivo and in vitro evidence) by regulating autophagy. ${ }^{63}$ Berbamine acts on this pathway and based on growing evidence, the hypothesis of using Berbamine in diabetic nephropathy can be advanced.

\section{Asthma and allergic disorder}

The role of stat and inflammation is thoroughly discussed. ${ }^{64,65}$ Berbamine, a well-known anti- 
inflammatory and STAT 3 inhibitor, can be used to treat asthma.

\section{CONCLUSION}

Berbamine being STAT 3 inhibitor, antioxidant, antiinflammatory and modulator of many signalling pathway it must be explored in autoimmune diseases, may help treat diseases like obesity, metabolic syndrome, inflammatory syndrome, sepsis, COVID-19, dengue fever, Nipah virus infection, influenza, solid tumors, lymphoma, cancer, hematological malignancies, skin inflammatory disorder, atopic dermatitis, psoriasis, allergic asthma, liver regeneration, diabetic nephropathy, brain injury, newborn hypoxia-ischemia, ischemic brain damage, nerve regeneration, fibrotic disease, autoimmune diseases like rheumatoid arthritis, SLE, lupus nephritis, inflammatory bowel diseases.

Funding: No funding sources

Conflict of interest: None declared

Ethical approval: Not required

\section{REFERENCES}

1. Cheng XX, Lui Y, Zhou B, Xiao XH, Liu Y. Probing the binding sites and the effect of berbamine on the structure of bovine serum albumin. Spectrochim Acta A Mol Biomol Spectrosc. 2009;72(5):922-8.

2. Wang S, Liu Q, Zhang Y, Liu K, Yu P, Liu K, et al. Suppression of growth, migration and invasion of highly-metastatic human breast cancer cells by Berbamine and its molecular mechanisms of action. Mol Cancer. 2009;8(1):1-5.

3. Meng Z, Li T, Ma X, Wang X, VanNess C, Gan Y, et al. Berbamine inhibits the growth of liver cancer cells and cancer-initiating cells by targeting $\mathrm{Ca}^{2+} /$ calmodulin-dependent protein kinase II. Mol Cancer Therapeut. 2013;12(10):2067-77.

4. Wang S, Liu Q, Zhang Y, Liu K, Yu P, Liu K, et al. Suppression of growth, migration and invasion of highly-metastatic human breast cancer cells by Berbamine and its molecular mechanisms of action. Mol Cancer. 2009;8(1):1-5.

5. Hou ZB, Lu KJ, Wu XL, Chen C, Huang XE, Yin HT. In vitro and in vivo antitumor evaluation of berbamine for lung cancer treatment. Asian Pac J Cancer Prevent. 2014;15(4):1767-9.

6. Zhao Y, Lv JJ, Chen J, Jin XB, Wang MW, Su ZH, et al. Berbamine inhibited the growth of prostate cancer cells in vivo and in vitro via triggering intrinsic pathway of apoptosis. Prostate Cancer Prostatic Dis. 2016;19(4):358-66.

7. $\mathrm{Hu}$ B, Cai H, Yang S, Tu J, Huang X, Chen G. Berbamine enhances the efficacy of gefitinib by suppressing STAT3 signaling in pancreatic cancer cells. Onco Targets Ther. 2019;12:11437.

8. Zhang H, Jiao Y, Shi C, Song X, Chang Y, Ren Y, et al. Berbamine suppresses cell proliferation and promotes apoptosis in ovarian cancer partially via the inhibition of Wnt/ $\beta$-catenin signaling. Acta Biochimica Biophysica Sinica. 2018;50(6):532-9.

9. Yang F, Nam S, Brown CE, Zhao R, Starr R, Horne $\mathrm{DA}$, et al. A novel berbamine derivative inhibits cell viability and induces apoptosis in cancer stem-like cells of human glioblastoma, via up-regulation of miRNA-4284 and JNK/AP-1 signaling. PloS one. 2014;9(4):94443.

10. Mou L, Liang B, Liu G, Jiang J, Liu J, Zhou B, et al. Berbamine exerts anticancer effects on human colon cancer cells via induction of autophagy and apoptosis, inhibition of cell migration and MEK/ERK signaling pathway. J BUON. 2019;24(5):1870-5.

11. Han C, Wang Z, Chen S, Li L, Xu Y, Kang W, et al. Berbamine suppresses the progression of bladder cancer by modulating the ROS/NF- $\mathrm{B}$ axis. Oxidat Med Cell Longe. 2021.

12. Nam S, Xie J, Perkins A, Ma Y, Yang F, Wu J, et al. Novel synthetic derivatives of the natural product berbamine inhibit Jak2/Stat3 signaling and induce apoptosis of human melanoma cells. Mol Oncol. 2012;6(5):484-93.

13. Kapoor S, Liang Y, Qiu X, Xu RZ, Zhao XY. Emerging role of berbamine as an anti-cancer agent in systemic malignancies besides chronic myeloid leukemia. J Zhejiang Univ. 2012;13(9):761.

14. Zhu L, Zhang B, Lu X, Shu Y, Liu B. Delivery of paclitaxel and berbamine by polymeric carriers to cure gastric cancer. Preclinic Clinic Cancer Therapeut. 2013;20(7):265-74.

15. Zhang H, Jiao Y, Shi C, Song X, Chang Y, Ren Y, et al. Berbamine suppresses cell viability and induces apoptosis in colorectal cancer via activating p53dependent apoptotic signaling pathway. Cytotechnol. 2018;70(1):321-9.

16. Wang GY, Lv QH, Dong Q, Xu RZ, Dong QH. Berbamine induces Fas-mediated apoptosis in human hepatocellular carcinoma HepG2 cells and inhibits its tumor growth in nude mice. J Asian Nat Prod Res. 2009;11(3):219-28.

17. Zhu H, Ruan S, Jia F, Chu J, Zhu Y, Huang Y, et al. In vitro and in vivo superior radiosensitizing effect of berbamine for head and neck squamous cell carcinoma. Onco Target Ther. 2018;11:8117.

18. Liu L, Xu Z, Yu B, Tao L, Cao Y. Berbamine inhibits cell proliferation and migration and induces cell death of lung cancer cells via regulating c-Maf, PI3K/Akt, and MDM2-P53 pathways. Complement Alternat Med. 2021.

19. Zhang H, Zhu T, Fu R, Peng Y, Jing P, Xu W, et al. Combination of detoxified pneumolysin derivative $\triangle \mathrm{A} 146 \mathrm{Ply}$ and berbamine as a treatment approach for breast cancer. Mol Ther Oncolytic. 2020;18:247-61.

20. Jia XJ, Li X, Wang F, Liu HQ, Zhang DJ. Berbamine exerts anti-inflammatory effects via inhibition of NF$\kappa \mathrm{B}$ and MAPK signaling pathways. Cell Physiol Biochem. 2017;41(6):2307-18.

21. Wang GY, Zhang JW, Lü QH, Xu RZ, Dong QH. Berbamine induces apoptosis in human hepatoma cell line SMMC7721 by loss in mitochondrial 
transmembrane potential and caspase activation. J Zhejiang Univ. 2007;8(4):248-55.

22. Kapoor S, Liang Y, Qiu X, Xu RZ, Zhao XY. Emerging role of berbamine as an anti-cancer agent in systemic malignancies besides chronic myeloid leukemia. J Zhejiang Univ. 2012;13(9):761.

23. Yang S, Yang S, Zhang H, Hua H, Kong Q, Wang J, et al. Targeting $\mathrm{Na}^{+} / \mathrm{K}^{+}$-ATPase by berbamine and ouabain synergizes with sorafenib to inhibit hepatocellular carcinoma. Bri J Pharmacol. 2021.

24. Tyler J. Natural product berbamine enhances the efficacy of doxorubicin treatment for triple negative breast cancer. Univ Ther. 2020:5763.

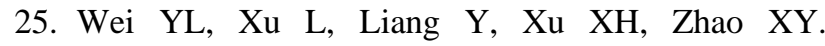
Berbamine exhibits potent antitumor effects on imatinib-resistant CML cells in vitro and in vivo. Acta Pharmacologica Sinica. 2009;30(4):451-7.

26. Zhao Y, Tan Y, Wu G, Liu L, Wang Y, Luo Y, et al. Berbamine overcomes imatinib-induced neutropenia and permits cytogenetic responses in Chinese patients with chronic-phase chronic myeloid leukemia. Int $\mathbf{J}$ Hematol. 2011;94(2):156-62.

27. Yang S, Yang S, Zhang H, Hua H, Kong Q, Wang J, et al. Targeting $\mathrm{Na}^{+} / \mathrm{K}^{+}$-ATPase by berbamine and ouabain synergizes with sorafenib to inhibit hepatocellular carcinoma. Br J Pharmacol. 2021.

28. Xu R, Dong Q, Yu Y, Zhao X, Gan X, Wu D, et al. Berbamine: a novel inhibitor of bcr/abl fusion gene with potent anti-leukemia activity. Leukemia Res. 2006;30(1):17-23.

29. Yang F, Nam S, Zhao R, Tian Y, Liu L, Horne DA, et al. A novel synthetic derivative of the natural product Berbamine inhibits cell viability and induces apoptosis of human osteosarcoma cells, associated with activation of JNK/AP-1 signaling. Cancer Biol Ther. 2013;14(11):1024-31.

30. Ling-Jun H, Ting-Yi J, Chao P, Wan-Lin W, Chang DM, Chang SY, et al. Plant alkaloid tetrandrine downregulates I [kappa] B [alpha] kinases-I [kappa] B [alpha]-NF-[kappa] B signaling pathway in human peripheral blood $\mathrm{T}$ cell. $\mathrm{Br} \mathrm{J}$ Pharmacol. 2004;143(7):919.

31. Zhang CM, Gao L, Zheng YJ, Yang HT. Berbamine protects the heart from ischemia/reperfusion injury by maintaining cytosolic $\mathrm{Ca}^{2+}$ homeostasis and preventing calpain activation. Circul J. 2012;76(8):1993-2002.

32. Jia F, Ruan S, Liu N, Fu L. Synergistic antitumor effects of berbamine and paclitaxel through ROS/Akt pathway in glioma cells. Complement Alternat Med. 2017.

33. Xin-Yu LI, Guan-Nan CH, Guo-Ming DU, Yue PA, Wu-Qi SO, Jiang TW, et al. Berbamine ameliorates ethanol-induced liver injury by inhibition of hepatic inflammation in mice. Chinese $J$ Nat Med. 2020;18(3):186-95.

34. Nam S, Xie J, Perkins A, Ma Y, Yang F, Wu J, et al. Novel synthetic derivatives of the natural product Berbamine inhibit JAK2/STAT3 signaling and induce apoptosis of human melanoma cells. Mol Oncol. 2012;6(5):484-93.

35. Xu H, Kong Y, Chen Y, Li N, Zhang S, Lu H. Natural plant extract berbamine is a potent inhibitor of cell growth and survival of human tenon's fibroblasts. Ophthal Res. 2020;63(6):555-63.

36. Kim YJ, Han JM, Jung HJ. Antiangiogenic and antitumor potential of berbamine, a natural CaMKII $\gamma$ inhibitor, against glioblastoma. Biochem Biophys Res Communic. 2021;566:129-34.

37. Huang L, Yuen TT, Ye Z, Liu S, Zhang G, Chu H, et al. Berbamine inhibits SARS-CoV-2 infection by compromising TRPMLs-mediated endolysosomal trafficking of ACE2. Signal Transduct Target Ther. 2021;6(1):1-3.

38. Teh BS, Seow WK, Li SY, Thong YH. Inhibition of prostaglandin and leukotriene generation by the plant alkaloids tetrandrine and Berbamine. Int $\mathbf{J}$ Immunopharmacol. 1990;12(3):321-6.

39. Sharma A, Anand SK, Singh N, Dwivedi UN, Kakkar P. Berbamine induced AMPK activation regulates mTOR/SREBP-1c axis and Nrf2/ARE pathway to allay lipid accumulation and oxidative stress in steatotic HepG2 cells. Eur J Pharmacol. 2020;882:173244.

40. Hudson AM, Lockard GM, Namjoshi OA, Wilson JW, Kindt KS, Blough BE, et al. Berbamine analogs exhibit differential protective effects from aminoglycoside-induced hair cell death. Front Cell Neurosci. 2020;14:234.

41. Zheng Y, Gu S, Li X, Tan J, Liu S, Jiang Y, et al. Berbamine postconditioning protects the heart from ischemia/reperfusion injury through modulation of autophagy. Cell Death Dis. 2017;8(2):2577.

42. Zheng Y, Gu S, Li X, Tan J, Liu S, Jiang Y, et al. Berbamine postconditioning protects the heart from ischemia/reperfusion injury through modulation of autophagy. Cell Death Dis. 2017;8(2):e2577.

43. Soni NO. Biodegradable nanoparticles for delivering drugs and silencing multiple genes or gene activation in diabetic nephropathy. Int J Life Sci Scienti Res. 2017;3(5):1329-38.

44. Soni NO. Drugs for diabetic nephropathy-full review. World J Pharm Pharmaceut Sci. 2017;6(7):1958-2022.

45. Soni NO. Embryonic life of HDACs inhibitor-in diabetic nephropathy. World J Pharm Pharmaceutical Sci. 2017;6:345-59.

46. Soni NO. TRPC 6 as a molecular target in diabetic nephropathy. Int $\mathrm{J}$ Life Sci Scienti Res. 2017;3(5):1311-4.

47. Soni NO. Resveratrol nanoparticle's formulation-in diabetic nephropathy. World J Pharm Pharmaceut Sci. 2017:368-86

48. Soni NO. Targeting DNA methyl transferase 1 [DNMT1]-in diabetic nephropathy. World J Pharma Pharma Sci. 2017;6(9):333-8.

49. Soni NO. Monaschin and ankaflavin-in diabetic nephropathy? World J Pharma Pharma Sci. 2017;6(9):327-2. 
50. Soni NO, Pawar SV, Kale S, Mane UA, Bhosale PU, Phandhare K, et al. Peroxisome proliferator-activated receptors and thiazolidinediones in diabetic nephropathy. Int $\mathrm{J}$ Basic Clinic Pharmacol 2019;8(10):2344.

51. Soni NO. Fructokinase inhibitors-in diabetic nephropathy. World J Pharma Pharma Sci. 2017;6(9).

52. Soni NO. FAP inhibitors: in diabetic nephropathy?. World J Pharma Pharma Sci. 2017;6(9):321-6.

53. Soni NO. Recombinant complement inhibitor CD59in diabetic nephropathy. In Diabetic Nephropathy. 2017;6(7):2056-60.

54. Soni NO. Current and future clinical application. Phosphodiesterase (PDEs). Inhibitors. 2017;8(7):1612-32.

55. Soni NO. A brief study about HDACs: Novel Pharmacological Target in diabetic nephropathy. New Forntiers Med Med Res. 2021;25:26-34.

56. Soni NO. NADPH oxidase is novel drug in diabetic nephropathy. World J Pharm Pharmaceutical Sci. 2017;6:765-5.

57. Soni NO. TGF-inhibitors are novel drugs-in diabetic nephropathy a review. World J Pharm Pharmaceut Sci. 2017:622-45.

58. Huang L, Lin T, Shi M, Chen X, Wu P. Liraglutide suppresses production of extracellular matrix proteins and ameliorates renal injury of diabetic nephropathy by enhancing Wnt/ $\beta$-catenin signaling. Am J Physiol Renal Physiol. 2020;319(3):458-68.

59. Zhang L, Pang S, Deng B, Qian L, Chen J, Zou J, et al. High glucose induces renal mesangial cell proliferation and fibronectin expression through $\mathrm{JNK} / \mathrm{NF}-\kappa \mathrm{B} / \mathrm{NADPH}$ oxidase/ROS pathway, which is inhibited by resveratrol. Int $\mathrm{J}$ Biochem Cell Biol. 2012;44(4):629-38.

60. Salatto CT, Miller RA, Cameron KO, Cokorinos E, Reyes A, Ward J, et al. Selective activation of AMPK $\beta 1$-containing isoforms improves kidney function in a rat model of diabetic nephropathy. J Pharmacol Experiment Therapeut. 2017;361(2):303-11.

61. Zheng C, Huang L, Luo W, Yu W, Hu X, Guan X, et al. Inhibition of STAT3 in tubular epithelial cells prevents kidney fibrosis and nephropathy in STZinduced diabetic mice. Cell Death Dis. 2019;10(11):14.

62. Wei M, Li Z, Xiao L, Yang Z. Effects of ROS-relative $\mathrm{NF}-\kappa \mathrm{B}$ signaling on high glucose-induced TLR4 and MCP-1 expression in podocyte injury. Mol Immunol. 2015;68(2):261-71.

63. Wen D, Tan RZ, Zhao CY, Li JC, Zhong X, Diao H, et al. Astragalus mongholicus Bunge and Panax notoginseng (Burkill) FH chen formula for renal injury in diabetic nephropathy-in vivo and in vitro evidence for autophagy regulation. Front Pharmacol. 2020;11:732.

64. Soni NO. Stat protein-a molecular target in asthma. History. 2016;3:4.

65. Soni NO. Nuclear factor-kappa-b-as molecular target in asthma. World J Pharma Pharma Sci. 2017;5(7):481-98.

Cite this article as: Soni NO. Berbamine application beyond cancer. Int J Basic Clin Pharmacol 2021;10:1221-6. 